Original Research Article

\title{
Comparative study of USG guided aspiration and non-aspiration cytology for evaluation of specimen quality and diagnostic accuracy in abdominal and pelvic lumps
}

\author{
Bundela A. ${ }^{1}$, Bundela A. ${ }^{2}$, Vahikar S.U. ${ }^{3}$, Srivastava K. ${ }^{4}$ \\ ${ }^{1}$ Dr. Archana Bundela, Assistant Professor, ${ }^{2}$ Dr. Alpana Bundela, Assistant Professor, ${ }^{3}$ Dr. Shilpa U. Vahikar, Associate \\ Professor, ${ }^{4}$ Dr. Kanchan Srivastava, Associate Professor; all authors are attached with Department of Pathology, B.R.D. \\ Medical College Gorakhpur.
}

Corresponding Author: Dr. Alpana Bundela, Assistant Professor, Department of Pathology, B.R.D. Medical College Gorakhpur. Email: abundela5@gmail.com

\begin{abstract}
Introduction: The aim of this study was to compare the efficacy of USG guided fine needle aspiration cytology (FNAC) with that of fine needle non aspiration cytology (FNNAC) in abdominal, pelvic masses. Objectives: Although a large volume of data is available to compare FNAC and FNNAC sampling in superficial lesions, very less literature is available regarding FNNAC for abdominal and pelvic masses. Therefore we have directly compared the diagnostic accuracy and specimen quality of both techniques FNAC and FNNAC under guidance of ultrasound in intra abdominal and pelvic mass lesions. Method: Samples were obtained by applying both FNAC and FNNAC techniques for abdominal, pelvic lumps of 71 patients who attended the pathology department of BRD Medical College Gorakhpur, Uttar Pradesh. The sampling procedure were done by single operator, smears made from FNAC and FNNAC techniques were studied using a objective scoring system based on the background blood or clot, amount of cellular material, degree of cellular degeneration, degree of cellular trauma and retention of appropriate architecture and then comparison of diagnosed case was done with histopathology. Results: The overall diagnostic accuracy was $85.9 \%$ in FNAC and $83.0 \%$ in FNNAC ( $\mathrm{p}=0.80)$. Diagnostic accuracy by FNAC are $83.3 \%, 92.8 \%, 91.6 \%$ in cases of liver, gallbladder and ovary respectively. In cases of G.I.T masses it is $81.9 \%$ by FNAC.Diagnostic accuracy by FNNAC it is maximum $93.4 \%$ in cases of liver masses and lower in ovarian masses (66.6\%) when compared with the histopathology. A statistically insignificant difference was recorded in sampling technique score for quality of smears in all cases except in the liver where the FNNAC score was statistically significant. Conclusion: Although both techniques have their own advantages and disadvantages but diagnostic accuracy was much better by FNAC than FNNAC but quality of smears for cytodiagnosis was superior by FNNAC technique than FNAC in all abdominal, pelvic masses.
\end{abstract}

Key words: Aspiration, Fine needle, Non aspiration, Fine needle Ultrasound Aspiration.

\section{Introduction}

The abdominal-pelvic masses remain enigma in surgical Practice. Two Cyto-diagnostic techniques have been described to obtain cytology samples using a fine needle [1]. The first method, fine needle non aspiration sampling, entails placing a hollow needle within a lesion, removing the stylet and moving it back and forth, which allows the capillary action of needle to draw sample into the chamber without applying an external force. The alternative method, fine needle aspiration technique, uses a syringe to produce a negative pressure within the needle chamber.

Manuscript received: $28^{\text {th }}$ October 2018

Reviewed: $07^{\text {th }}$ November 2018

Author Corrected: $14^{\text {th }}$ November 2018

Accepted for Publication: $20^{\text {th }}$ November 2018
This technique was introduced in 1960, because of the limited use of fine needle non aspiration method in cases of sclerotic lesion, deep and small lesions. Although FNAC is more traumatic than non aspiration

technique it is thought to, more amount of material is obtained than non aspiration method [2]. Comparisons of FNAC and FNNAC sampling have been performed in superficial lumps with conflicting results $[3,4]$. The present study was performed to compare diagnostic accuracy and specimen quality of ultrasound guided FNAC and FNNAC sampling techniques in intraabdominal and pelvic masses. 


\section{Original Research Article}

\section{Material and Method}

This prospective study was carried out in the department of pathology with the help of department of Radio diagnosis in B.R.D medical college Gorakhpur U.P, covering the period of 18 months from May 2008 to November 2009. A total 71 patient presenting with abdominal- pelvic mass lesions were included in this study. After proper work up including detailed clinical history, examination and their routine investigations, provisional diagnosis was made, before they were subjected for non- aspiration and aspiration techniques for rapid cytodiagnosis in every case. patients were excluded from the study if they had severe coagulopathy( international normalized ratio [INR] $>2$ ) or if there is any physical encumbrance for doing procedure such as a vascular structure obstructing the path of needle.Fine needle non aspiration cytology (FNNAC) was done under ultrasonographic guidance in the presence of a qualified radiologist with the help of 22-24 gauge spinal needle without a syringe and it was followed by fine needle aspiration cytology (FNAC) with 22 gauge spinal needle attached to $20 \mathrm{ml}$ syringe. FNNAC was performed by holding the needle directly with finger tips and inserting it into the target lesion. After reaching the site needle was moved back and forth in various directions at different depths. The needle was taken out from the site and connected to a syringe filled with air. Cellular material was then expelled onto a glass slide. Uniform and thinly spread smears were obtained by superimposition technique. Both cytotechniques were done at same time and slides were made by single operator, avoiding bias in all stages of sampling. Smears were stained with May-Grunwald Giemsa (MGG) and Hematoxylin and Eosin (H\&E) stain was used for the alcohol fixed smears. A cytologic diagnosis was rendered for each case and each individual slide was objectively analyzed using a point scoring system [4] to enable accurate comparison between fine needle aspiration and non aspiration techniques as shown in Table.1. On the basis of five criteria tabulated, a cumulative score was obtained for each specimen which was then categorized accordingly to one of the 3 categories as, unsuitable for cytodiagnosis (score, 0-2), adequate for cytodiagnosis (score, 3-6) or diagnostically superior (score, 7-10). The cytological diagnoses were correlated with the histopathological diagnosis as histopathology is considered to be the gold standard.

Table-1: Modified scoring system used in the interpretation of cytological features.

\begin{tabular}{|c|c|c|c|}
\hline Criteria & Description & & Point sore \\
\hline \multirow[t]{5}{*}{ Background blood or clot } & Large amount & Great compromise to diagnosis & 0 \\
\hline & Large amount & Diagnosis still possible & 0.5 \\
\hline & Moderate & Diagnosis possible & 1.0 \\
\hline & Moderate & Diagnosis evident & 1.5 \\
\hline & Minimal & Excellent quality & 2.0 \\
\hline \multirow[t]{5}{*}{ Amount of cellular material } & Absent & Diagnosis not possible & 0 \\
\hline & Minimal & Diagnosis still possible & 0.5 \\
\hline & Moderate & Sufficient for diagnosis & 1.0 \\
\hline & Moderate to abunda & Diagnosis evident & 1.5 \\
\hline & Abundant & Diagnosis simple, excellent quality & 2.0 \\
\hline \multirow[t]{5}{*}{ Degree of cellular degeneration } & Marked & Diagnosis impossible & 0 \\
\hline & Marked & Diagnosis still possible & 0.5 \\
\hline & Moderate & Diagnosis possible & 1.0 \\
\hline & Moderate & Diagnosis evident & 1.5 \\
\hline & Minimal & Diagnosis easy & 2.0 \\
\hline \multirow[t]{5}{*}{ Degree of cellular trauma } & Marked & Diagnosis impossible & 0 \\
\hline & Marked & Diagnosis still possible & 0.5 \\
\hline & Moderate & Diagnosis possible & 1.0 \\
\hline & Moderate & Diagnosis evident & 1.5 \\
\hline & Minimal & Diagnosis easy & 2.0 \\
\hline \multirow[t]{5}{*}{ Retention of appropriate architecture } & Minimal to absent & Diagnosis impossible & 0 \\
\hline & Minimal & Diagnosis still possible & 0.5 \\
\hline & Moderate & Some preservation, follicles, papillae, acini etc. & 1.0 \\
\hline & Moderate & Diagnosis evident & 1.5 \\
\hline & Excellent & $\begin{array}{l}\text { Excellent architectural display closely } \\
\text { reflecting histological diagnosis }\end{array}$ & 2.0 \\
\hline
\end{tabular}

Pathology Update: Tropical Journal of Pathology \& Microbiology Available online at: www.pathologyreview.in 492 | P a g e 


\section{Original Research Article}

Statistical Analysis- Statistical tools from the worldwide web page www.staspage.org were used to perform descriptive analysis. All the results so obtained were interpreted statistically using the student's t-test

\section{Results}

Seventy one cases of abdominal - pelvic lesions were studied and maximum number of cases were in age group of 40 50 years and least number of cases were in age group of $0-10$ years. 48 patients $(67.6 \%)$ were male and 23 patients $(32.3 \%)$ were female. Thirty cases $(42.2 \%)$ were from liver followed by fourteen cases $(19.7 \%)$ from gallbladder, twelve cases $(16.9 \%)$ from ovary, eleven cases $(15.4 \%)$ from G.I.T. and four cases $(5.0 \%)$ from miscellaneous organs.

Among the thirty cases of liver, 19 (63.3\%) were metastatic adenocarcinoma, 06 cases (20.0\%) were hepatocellular carcinoma, 04 cases (13.3\%) were pyemic liver abscess and 01 case $(3.33 \%)$ was hemangioma. Out Of 14 Cases from gallbladder, 12 Cases (85.7\%) were adenocarcinoma and 2 Cases (14.2\%) were Inflammatory (Empyema).

05 cases $(41.6 \%)$ out of 12 cases of ovary were serous cystadenocarcinoma, 04 cases $(33.3 \%)$ were mucinous cystadenocarcinoma, 2 cases $(16.6 \%)$ were dysgerminoma and 01 case $(8.33 \%)$ was yolk sac tumor. In the GIT 04 Cases (36.3\%) were colon carcinoma, 4 cases $(36.3 \%)$ were chronic nonspecific inflammatory lesion and 3 cases (27.2\%) were tubercular enteritis.

FNAC smears had more blood contamination than FNNAC smears in all cases and the difference between the techniques was statistically significant in liver, gallbladder and ovary $(\mathrm{P}<0.01,0.003$, and $\mathrm{P}<0.01)$ respectively except G.I.T (0.13).Table-2, Fig.3,4,5.

Table 2: Comparison of cytological features in the abdominal -pelvic organs

\begin{tabular}{|c|c|c|c|c|c|}
\hline Site & $\begin{array}{c}\text { Background } \\
\text { blood clot }\end{array}$ & $\begin{array}{c}\text { Amount of } \\
\text { cellular material }\end{array}$ & Degeneration & Cell trauma & $\begin{array}{l}\text { Maintenance } \\
\text { of architecture }\end{array}$ \\
\hline \multicolumn{6}{|l|}{ Liver(n=30) } \\
\hline FNNAC & $1.63 \pm 0.566$ & $1.200 \pm 0.484$ & $1.630 \pm 0.556$ & $1.309 \pm 0.643$ & $1.260 \pm 0.520$ \\
\hline FNAC & $1.160 \pm 0.58$ & $1.360 \pm 0614$ & $1.26 \pm 0.583$ & $1.071 \pm 0.341$ & $0.520 \pm 0.210$ \\
\hline $\mathrm{P}$ value & $<0.01$ & $>0.05$ & $<0.05$ & $>0.05$ & $<0.01$ \\
\hline \multicolumn{6}{|c|}{ Gallbladder(n=14) } \\
\hline FNNAC & $1.280 \pm 0.468$ & $1.375 \pm 0.496$ & $1.420 \pm 0.512$ & $1.070 \pm 0.474$ & $1.357 \pm 0.496$ \\
\hline FNAC & $0.714 \pm 0.468$ & $1.280 \pm 0.611$ & $1.070 \pm 0.474$ & $1.357 \pm 0.496$ & $0.920 \pm 0257$ \\
\hline $\mathrm{p}$-value & $<0.003$ & $>0.05$ & $>0.05$ & $>0.05$ & $<0.01$ \\
\hline \multicolumn{6}{|l|}{ Ovary $(\mathrm{n}=12)$} \\
\hline FNNAC & $1.33 \pm 0.346$ & $0.580 \pm 0.484$ & $1.200 \pm 0.484$ & $0.66 \pm 0.486$ & $0.916 \pm 0.493$ \\
\hline FNAC & $0.916 \pm 0.276$ & $1.290 \pm 0.62$ & $1.023 \pm 0.348$ & $1.00 \pm 0.574$ & $0.916 \pm .0 .493$ \\
\hline $\mathrm{p}$-value & $<0.01$ & $<0.01$ & $>0.05$ & $>0.05$ & $>.99$ \\
\hline \multicolumn{6}{|l|}{ G.I.T $(n=11)$} \\
\hline FNNAC & $0.660 \pm 0.486$ & $1.02 \pm 0.417$ & $1.02 \pm 0.147$ & $1.020 \pm 0.319$ & $0.630 \pm 0.298$ \\
\hline FNAC & $1.000 \pm 0574$ & $0.59 \pm 0.298$ & $059 \pm 0.312$ & $0.520 \pm 0.312$ & $0.997 \pm 0.660$ \\
\hline $\mathrm{P}$ - value & 0.13 & $>.05$ & 0.04 & .001 & $>0.05$ \\
\hline \multicolumn{6}{|l|}{$\begin{array}{l}\text { Miscellaneous } \\
\quad(n=4)\end{array}$} \\
\hline FNNAC & $1.00 \pm 0.707$ & $0.75 \pm 0.801$ & $1.020 \pm 0.741$ & $0.75 \pm 0.830$ & $0.981 \pm 0.707$ \\
\hline FNAC & $0.75 \pm 0830$ & $0.75 \pm 0.731$ & $0.68 \pm 0.789$ & $0.99 \pm 0.810$ & $0.98 \pm 0.707$ \\
\hline P-value & $>0.05$ & $>0.05$ & .55 & .69 & $>0.05$ \\
\hline Total $(n=71)$ & & & & & \\
\hline
\end{tabular}

Values are mean +S.D. Significance was determined by using Student's t-test 


\section{Original Research Article}

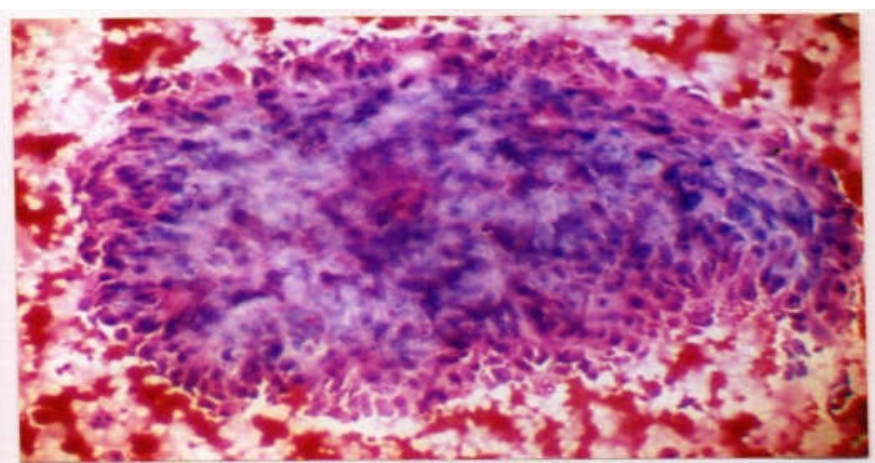

Fig.-2: Fine needle aspiration cytology of metastatic adenocarcinoma of gallbladder showing sheet of tumour cells on a hemorrhagic background (H\&E stain $x$ 40)

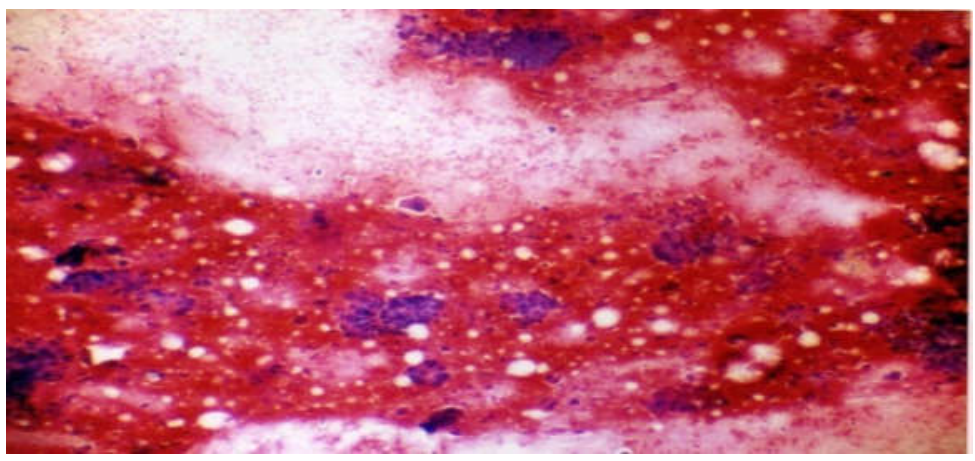

Fig.-3: Fine needle aspiration cytology of mucinous cystadenocarcinoma showing groups and clusters of tumour cells in hemorrhagic background ( $H$ \& $E$ stain $x$ 40)

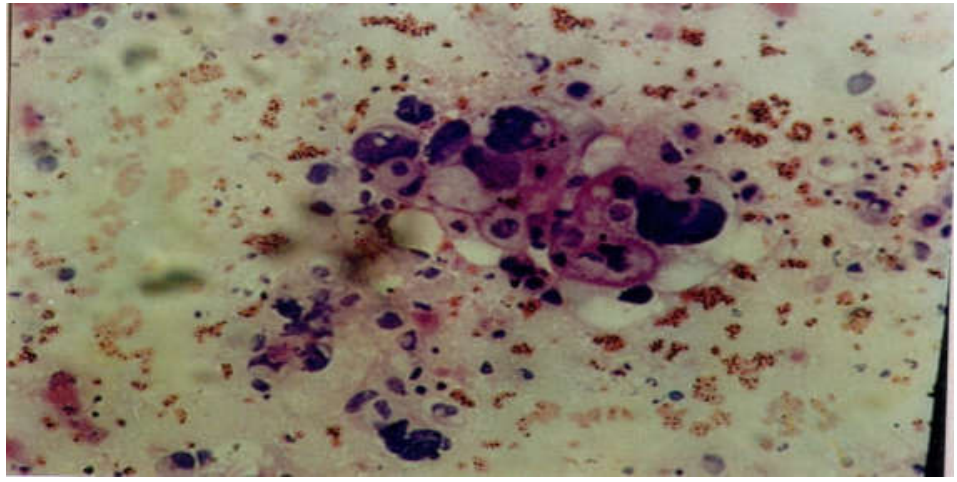

Fig-4: Non aspiration cytology of mucinous cystadenocarcinoma ovary (H \& E stain x 40)

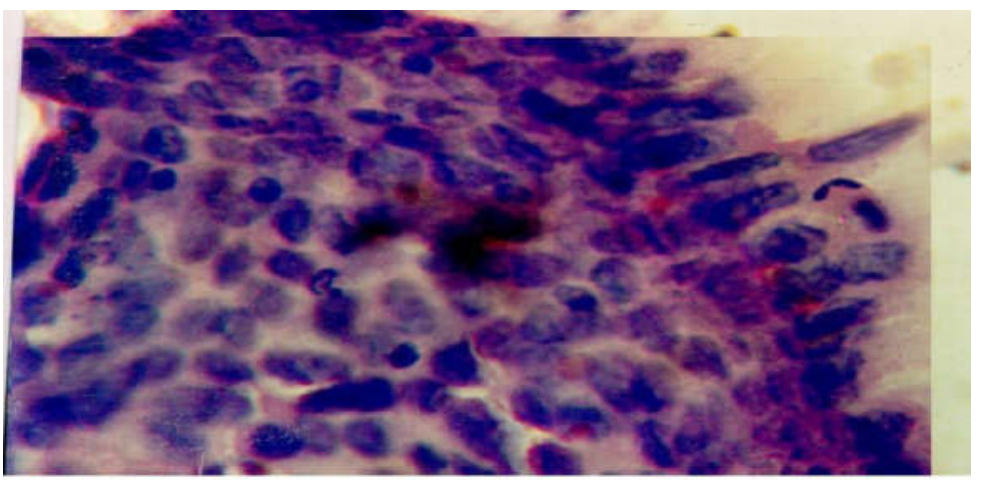

Fig.-5: Non aspiration cytology of colon carcinoma, tumour cells showing palisading pattern (H\&E stain $x$ 40) 


\section{Original Research Article}

on comparison of the score for both the technique for amount of cellular material dislodged over the slide it was found to be more in a aspiration smears than non aspiration smears but statistically superiority was seen only for ovarian masses $(\mathrm{P}<0.01)$. Greater degree of cellular degeneration was found in FNAC in all cases but this difference was statistically significant for liver and ovary $(<0.05)$.

Cellular trauma was greater in FNAC smears as there is presence of increased clumping of cells and smudging of chromatin. With back and forth movement or rotation of bevel of needle cell trauma is increased.fig. 2

Non-aspiration smears yielded better retention of architecture with similar findings reported by others. Statistically significant difference was observed in liver and gallbladder $(\mathrm{P}<0.01)$. fig.2. There was a statistically insignificant difference in sampling technique score in all cases except in the liver where the FNNAC score was statistically significant $(\mathrm{P}<0.01)$ (Table $-2,3)$

Table-3: Total \&Average points scored for all cases

\begin{tabular}{|c|c|c|c|c|c|}
\hline Name of lesion & No. of cases & \multicolumn{2}{|c|}{ FNAC Cytology } & \multicolumn{2}{|c|}{ FNNAC Cytology } \\
\hline Liver & 30 & 151 & 5.03 & 162 & 5.40 \\
\hline Gallbladder & 14 & 75 & 5.40 & 100 & 7.14 \\
\hline Ovary & 12 & 66 & 5.50 & 71 & 5.96 \\
\hline G.I.T & 11 & 56 & 5.09 & 59 & 5.33 \\
\hline Miscellaneous & 4 & 22 & 5.50 & 28 & 7.00 \\
\hline
\end{tabular}

On analyzing the average scores of each sampling technique for different organs, scores are high in fine needle non aspiration (FNNAC) method (Table 3).

On categorizing all the smears obtained by FNAC and FNNAC technique on the basis of scores obtained it was apparent that by FNAC we obtained greater number of diagnostically adequate (43) and lesser number of unsatisfactory smears (05) whereas by FNNAC technique we get 30 cases as diagnostically superior and 09 cases as insufficient for diagnosis. Table 4

Table-4: Comparison of quality of smears obtained by FNC -A and FNC- NA

\begin{tabular}{|c|c|c|c|}
\hline Quality of smear & FNAC & FNNAC & p-Value \\
\hline Superior (7-10) & 23 & 30 & 0.12 \\
\hline Diagnostic(3-6) & 43 & 32 & $<0.03$ \\
\hline Superior + Diagnostic(3-10) & 66 & 62 & 0.2 \\
\hline Insufficient(0-2) & 05 & 09 & - \\
\hline Total & $\mathbf{7 1}$ & $\mathbf{7 1}$ & \\
\hline
\end{tabular}

The overall diagnostic accuracy was $85.9 \%$ in FNAC and $83.0 \%$ in FNNAC ( $\mathrm{p}=.08)$. Diagnostic accuracy by FNAC are $83.3 \%, 92.8 \%, 91.6 \%$ in cases of liver, gallbladder and ovary respectively. In cases of GIT masses it is $81.9 \%$ by FNAC. Diagnostic accuracy by FNNAC, is maximum $93.4 \%$ in cases of liver masses and lower in ovarianmasses $(66.6 \%)$ when compared with the histopathology (Table - 5)

Table-5: Comparison of stepwise and overall diagnostic accuracy of FNNAC and FNAC

\begin{tabular}{|c|c|c|c|c|}
\hline Site & $\begin{array}{c}\text { Histopathology } \\
\text { obtained }\end{array}$ & $\begin{array}{c}\text { Diagnostic accuracy by } \\
\text { FNNAC }\end{array}$ & $\begin{array}{c}\text { Diagnostic accuracy by } \\
\text { FNAC }\end{array}$ & p-value \\
\hline Liver & 30 & $28(93.4 \%)$ & $25(83.3 \%)$ & 0.4 \\
\hline Gallbladder & 14 & $12(85.7 \%)$ & $13(92.8 \%)$ & $>0.05$ \\
\hline Ovary & 12 & $8((66.6 \%)$ & $11(91.6 \%)$ & 0.3 \\
\hline G.I.T & 11 & $08(72.8 \%)$ & $9(81.9 \%)$ & $>0.05$ \\
\hline Miscellaneous & 04 & $03(75.0 \%)$ & $03(75.0 \%)$ & $>.9$ \\
\hline Total & $\mathbf{7 1}$ & $\mathbf{5 9}(\mathbf{8 3 . 0} \%)$ & $\mathbf{6 1}(\mathbf{8 5 . 9} \%)$ & $\mathbf{. 8 0}$ \\
\hline
\end{tabular}




\section{Original Research Article}

\section{Discussion}

Fine needle cytology is gaining popularity as a means of diagnosing mass lesions in intra-abdominal organs. It has now proved to be superior to core- needle or open biopsy in terms of cost, procedure, associated morbidity and early diagnosis [5]. The present study has been undertaken to evaluate the acceptability, reliability and accuracy of FNNAC in comparison with FNAC in intra abdominal and pelvic mass lesions.

In our study the age of patients ranged from 7 to 78 years, with most patients being in age group of 40-50 years. This finding is comparable with those obtained by Mangal et al [6].

This could be because malignancies are most common in age group of 40-60 years, Dam L. Lango [7] stated that most significant risk for cancer is age. In previous studies where all intra abdominal organs were considered, Liver constituted the single largest group subjected to FNAC, After liver masses, gall bladder was second most common organ subjected for cytodiagnosis [8]. These findings are similar to our study.

Present series included study of 30 patients of liver lump. Out of that, maximum number of cases were diagnosed as metastatic adenocarcinoma, A Rasania et al [9] found that metastatic tumours were more common (70.4\%) than hepatocellular carcinoma which accounted for $26.2 \%$ of total malignant liver disease.

Fagelman D and Quintus Chess [10] found 90\% diagnostic accuracy in 40 consecutive fine needle liver biopsies performed by using the non aspiration technique. $93.4 \%$ diagnostic accuracy was found in present study, where non aspiration method was applied in 30 cases of liver masses.

In case of Gall bladder lumps $92.8 \%$ diagnostic accuracy was reported. Similar findings were comparable with those obtained by Nigam et al [11] but different from those from a study by Nautiyal $\mathrm{S}$ et al [8].

Diagnostic accuracy of ovarian masses was reported $91.6 \%$ by aspiration method and $66.6 \%$ by non aspiration method. While $80.9 \%$ diagnostic accuracy by FNAC technique was reported by Mehdi G et al [12]. Cytodiagnosis of Gastro intestinal masses done by Nautiyal $\mathrm{S}$ et al [8] was revealed $100.0 \%$ diagnostic accuracy, which is different, $81.9 \%$ \& $72.8 \%$ by FNAC and FNNAC respectively in present study.

Comparison of specimen quality for five parameters was done between both techniques FNNAC and FNAC. FNNAC had less blood contamination than FNAC in all cases. Other worker [1] tried to explain the reason that this could be because the specimen by FNNAC technique obtained by spontaneous capillary action without much trauma to tissue.Cellular yield was more or less comparable for both techniques but statistical superiority was seen only for ovarian masses.However Mair et al [3] and Zajdela et al [13] did not find any significant difference in smears prepared by both techniques, but our findings were similar to Jayaram and Gupta [14]. Available literature on cellular trauma, degeneration and retention of architecture revealed less cellular degeneration and retention of architecture revealed less cellular trauma in FNNAC as compared to FNAC [14-15]. Non aspiration yielded better retention of architecture fig 3, fig 4 with similar findings reported by Ghosh et al [16] and Misra RK et al [17].

For the five parameters studied objectively,there was a statistically insignificant difference in sampling technique scores in all cases except in liver,these results were comparable with those obtained by Fagelman D et al [10].Categorizing all the smears obtained by FNAC and FNNAC on the basis of theirscore according to predetermined criteria greater number of diagnostically adequate specimen were obtained by FNAC than FNNAC but the number of diagnostically superior specimen obtained by FNNAC technique was found to be more than that by FNAC. This difference was found statistically significant.However the number of inadequate smears was also more by FNNAC technique than by FNAC. Similar findings were recorded by Malik NP et al [18], Batra Rajeev et al [19] this results were different from Santos and Leiman [20].

The clinical value of cytology is not limited to neoplastic conditions. It is also valuable in diagnosis of inflammatory, infectious and degenerating conditions. FNNAC seems to be better for diagnosing malignant lesions while FNAC appeared better for diagnosing benign lesions $[14,15]$. FNAC was considered as the procedure of choice for cystic lesions as the fluid could be collected for cytological evaluation, according to them better Diagnostic results could be obtained if both the techniques are used together [17].

Pathology Update: Tropical Journal of Pathology \& Microbiology Available online at: www.pathologyreview.in 496 | P a g e 


\section{Original Research Article}

Santos and leiman [20] explained that scientific basis of non aspiration technique. The technique employing insertion of a fine needle into a lesion without attachment of a syringe, depends on the property of capillary tension in narrow channels (that is outer diameter of 22 gauge needle is $0.6 \mathrm{~mm}$ ) The physical principle is the state that a fluid (semi solid substance) will ascend spontaneously in a narrow tube in inverse proportion to diameter of tube/ capillary

This ascent of fluid is governed by formula $\mathrm{h}=2 \mathrm{~T} / \mathrm{pgr}$, where $\mathrm{h}$ is the Height attained, $\mathrm{T}$ is the surface tension of fluid, $\mathrm{P}$ is the density of that fluid, $g$ is the gravity and $r$ is the radius (Figure-1).

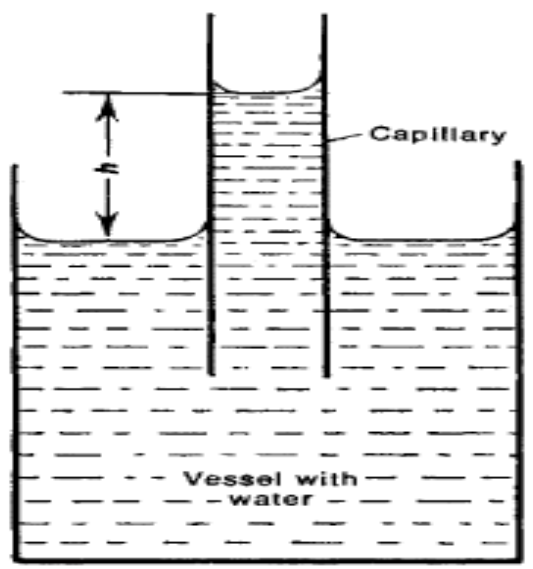

fig. $1 \mathrm{~h}=2 \mathrm{~T} / \mathrm{pgr}$

Out of 71 cases of abdominal- pelvic masses, diagnosis was made in greater number of cases by FNAC compared to FNNAC. While the quality of smears was superior in FNNAC, and this finding is consistent with Mishra R.K et al [17] and Ghosh et al [16].

\section{Conclusion}

Paucity of work is available regarding role of FNNAC in intra-abdominal-pelvic masses, this study contributes, by reporting comparative study of FNNAC and FNAC in terms of diagnostic accuracy and specimen quality in such lesions. In abdominal- pelvic masses, USG guided FNNAC may be more efficient adjuvant method of sampling. It provides 'superb quality' of smears with superior diagnostic value, although FNAC can also diagnose most lesions. FNAC was most likely to be diagnostically superior to FNNAC. In addition benign lesions or abscess can be drained by aspiration for therapeutic reason.

It was concluded that using both methods simultaneously in each lesion considerably increase the efficiency of samples for cytological diagnosis.

Acknowledgments: We wish to thank our co-authors and pathologist Dr Shilpa, Dr Alpana and Dr K. Srivastava and all the members of department of pathology and radiology for their valuable contribution in present study.

\section{References}

1. Castaneda- Zuniga W (editor); Interventional Radiology: Third Edison, Volume 2. Baltimore, Williams \& Wilkins, 1997, p 1795.
2. Das DK. Fine-needle aspiration cytology: its origin, development, and present status with special reference to a developing country, India. Diagn Cytopathol. 2003 Jun; 28 (6): 345-51. DOI:10.1002/dc.10289

3. Mair S, Dunbar F, Becker PJ, et al. Fine needle cytology--is aspiration suction necessary? A study of 100 masses in various sites. Acta Cytol. 1989 Nov-Dec; 33 (6):809-13.

4.Ceresini G, Corcione L, Morganti S, Milli B, Bertone $\mathrm{L}$, Prampolini R, et al. Ultrasound-guided fine needle capillary biopsy of thyroid nodule, coupled with onsite cytologic review, improves results. Thyroid. clinical research report 2004 May 9; 14 (5): 385389

5. Barbhiya M, Bhunia S, Gupta S. Gallbladder cancer incidence in Gwalior district of India: five year trend based on registry of a regional cancer centre. Indian $\mathrm{J}$ cancer.2012. july;49(2), 249-57

6. Mangal N, Sharma VK, Verma N, et al. Ultrasound guided fine needle aspiration cytology in the diagnosis of retroperitoneal masses: A study of 85 cases. J Cytol. 2009 Jul;26(3):97-101. doi: 10.4103/0970-9371. 59394. 


\section{Original Research Article}

7. Dam L. Lango ; Approach to the patients with cancer : Harrison's principle of internal medicine, 15 th edi; 493-499

8. Nautiyal S, Mishra RK,Sharma SP. Routine and ultrasound guided FNAC of intra-abdominal lumps- a comparative study . J cytol. 2004 May;. 21 (3): 129-32.

9. Rasania A, Pandey CL, Joshi N. Evaluation of FNAC in diagnosis of Hepatic lesions; Journal of cytology. 2007 April;24(1):51-54.

10. Fagelman D, Chess Q. Non aspiration fine-needle cytology of the liver: a new technique for obtaining diagnostic samples. AJR Am J Roentgenol. 1990 Dec; 155 (6):1217-9.

11. Nigam SK, Paliwal U, Nigam N. Role of Fine needle aspiration cytology in the Intra-abdominal lumps. JEMDS 2014 March 3;3(9) 2395-2402. DOI: 10/14260/jemds/2014/2150 .

12. Mehdi G, Maheshwari V, Afzal S, Image-guided fine-needle aspiration cytology of ovarian tumors: An assessment of diagnostic efficacy. J Cytol. 2010 Jul;27 (3): 91-5. doi: 10.4103/0970-9371.71872.

13. Zajdela A, de Maublanc MA, Schlienger P, Haye C. Cytologic diagnosis of orbital and periorbital palpable tumors using fine-needle sampling without aspiration. Diagn Cytopathol. 1986 March;2(1):17-20. DOI org/ $10.10021002 / \mathrm{dc} .2840020105$
14. Jayaram N, Chetan M, Prasad SR, Ramaprasad AV. Thyroiditis: thyroid function and cytologic correlation: a study of 66 cases.J Cytol.1996 Jan-March;13(1):21-24

15. Raghuveer CV, Leekha I, Pai MR, et al. Fine Needle Aspiration cytology versus Fine Needle Sampling without aspiration. A prospective study of 200 cases. Indian J Med Sci. 2002 Sep;56(9):431-9.

16. Ghosh A, Misra RK, Sharma SP, et al. Aspiration vs non aspiration technique of cytodiagnosis--a critical evaluation in 160 cases. Indian J Pathol Microbiol. 2000 Apr;43(2):107-12.

17. Mishra RK, Mitra S, Jain R, Vahikar S, Bundela A, Misra P. Image guided Fine needle cytology with aspiration vs Non aspiration in Retroperitoneal Masses;Is Aspiration Necessary? J PatholTransl med 2015 March; 49(2):129-135doi10.4132/jptm.2015.01.28

18. Malik NP, Jain M, Sharma VKC et al. Comparison of Aspiration versus Non aspiration technique in thyroid lesions. Journal,Indian Academy of Clinical Medicine. 2013 Jan;14(1):20-22

19. Maurya AK, Mehta A, Mani NS, et al. Comparison of aspiration vs non-aspiration techniques in fine-needle cytology of thyroid lesions. J Cytol. 2010 Apr;27(2):514. doi: 10.4103/0970-9371.70737.

20. Santos JE, Leiman G. Non aspiration fine needle cytology. Application of a new technique to nodular thyroid disease. Acta Cytol. 1988 May-Jun;32(3):353-6.

\section{How to cite this article?}

Bundela A, Bundela A, Vahikar S.U, Srivastava K. Comparative study of USG guided aspiration and non-aspiration cytology for evaluation of specimen quality and diagnostic accuracy in abdominal and pelvic lumps. Trop J Path Micro 2018;4(7):491-498.doi:10.17511/jopm.2018.i07.03. 